\title{
Recirculação de água de lavagem de filtros e perigos associados a protozoários
}

\section{Filter backwash water recycling and protozoan-related hazards}

\begin{abstract}
Adiéliton Galvão de Freitas
Engenheiro Ambiental pela Universidade Federal de Viçosa (UFV). Mestre em Saneamento Ambiental pela UFV. Analista de Meio Ambiente da Companhia Energética de Minas Gerais (Cemig)

\section{Rafael Kopschitz Xavier Bastos}

Engenheiro Civil pela Universidade Federal de Juiz de Fora (UFJF). Especialista em Engenharia de Saúde Pública pela Escola Nacional de Saúde Pública da Fundação Oswaldo Cruz (ENSP/Fiocruz). PhD em Engenharia Sanitária pela University of Leeds, Inglaterra. Professor Associado do Departamento de Engenharia Civil da UFV
\end{abstract}

\section{Paula Dias Bevilacqua}

Veterinária pela UFV. Mestre em Epidemiologia pela Universidade Federal de Minas Gerais (UFMG). Doutora em Epidemiologia pela UFMG. Professora Associada do Departamento de Veterinária da UFV

\section{Valter Lúcio Pádua}

Engenheiro Civil pela UFMG. Mestre em Engenharia Sanitária pela Escola de Engenharia de São Carlos da Universidade de São Paulo (EESC/USP). Doutorado em Engenharia Sanitária pela EESC/USP). Professor Adjunto do Departamento de Engenharia Sanitária e Ambiental da UFMG

\section{João Francisco de Paula Pimenta}

Engenheiro Ambiental pela UFV. Mestrando em Saneamento Ambiental pela UFV

\section{Rosane Cristina de Andrade}

Engenheira Ambiental pela UFV. Mestranda em Saneamento Ambiental pela UFV

\section{Resumo}

Apresentam-se, neste trabalho, os resultados (i) da caracterização da água de lavagem de filtros (ALF) da estação de tratamento de água da Universidade Federal de Viçosa (ETA- UFV); (ii) de ensaios de clarificação da ALF em colunas de sedimentação, com e sem uso de polímeros; (iii) de ensaios de recirculação de ALF em ETA piloto (EP), sob condições variadas de razão de recirculação (5 a 20\% de incremento de vazão) e de turbidez da mistura de água bruta (AB) com ALF (12,1 a 257,3 uT). Na ALF foram encontradas concentrações em ordem de grandeza de $10^{1}$ cistos de Giardia spp. e oocistos de Cryptosporidium spp. por litro. Os resultados dos ensaios em coluna de sedimentação e de recirculação na EP demonstraram que a clarificação da ALF com uso de polímeros contribui para a minimização de perigos associados à introdução de cistos de Giardia e oocistos de Cryptosporidium.

Palavras-chave: água de lavagem de filtro; clarificação; Cryptosporidium spp.; Giardia spp.; recirculação; turbidez.

\section{Abstract}

This paper presents the results of (i) the characterization of the filter backwash water (FBW) of Viçosa University water treatment plant; (ii) trials of FBW clarification in sedimentation columns, with and without polymer application; (iii) trials of FBW recycling in a pilot plant, under variable conditions of recycling flow rates ( 5 to $20 \%$ of the raw water flow - RW) and of the influent water (RW + FBW) turbidity (12.1 to 257.3 UT). Around $10^{1}$ Giardia spp. cysts and Cryptosporidium spp. oocysts per liter were found in the FBW. The results of sedimentation columns and recycling trials demonstrated that FBW clarification using polymers contributes to minimize hazards related to the introduction of Giardia cysts and Cryptosporidium oocysts.

Keywords: clarification; Cryptosporidium spp.; filter backwash water; Giardia spp.; recycling; turbidity. 


\section{Introdução}

A água utilizada para a retrolavagem de filtros rápidos pode representar cerca de 5\%, ou mais, do volume total de água tratada, gerando grandes volumes de resíduos em curtos espaços de tempo. Assim, sob a ótica da minimização de impactos ambientais e da economia de água, tem crescido o interesse pela recirculação água de lavagem de filtros (ALF).

Entretanto, a prática de recirculação de ALF pode constituir introdução de perigos no processo de tratamento da água e implicar risco à saúde da população consumidora, associado, principalmente, à presença de cistos e oocistos de protozoários. Isso porque, como a filtração representa a principal etapa do tratamento responsável pela remoção de protozoários, muitas vezes a ALF contém concentrações mais elevadas de cistos ou oocistos do que a própria água bruta $(\mathrm{AB})$. Adicionalmente, em decorrência das dimensões reduzidas e da forma encistada, os protozoários, principalmente os oocistos de Cryptosporidium spp., podem passar pelos filtros e são pouco suscetíveis às doses de cloro utilizadas nas estações de tratamento de água (AROTA, GIOVANNI e LECHEVALIER, 2001; USEPA, 2002).

Nos Estados Unidos, a prática de recirculação de ALF é objeto de regulamentação especifica (USEPA, 2002), muito embora não sejam estabelecidos critérios explícitos de tratamento ou de qualidade da água. Em termos gerais, recomenda-se que a recirculação da ALF seja realizada com os devidos cuidados, dentre os quais se destacam a clarificação e o controle da razão de recirculação, com o intuito de impactar da menor forma possível a qualidade final da água tratada. Nos Estados da Califórnia e de Ohio, recomenda-se que a vazão de recirculação seja inferior a $10 \%$ da vazão da estação de tratamento de água (ETA) e no Estado de Maryland, inferior a $5 \%$ após clarificação com aplicação de polímeros. No Estado da Califórnia, recomenda-se, ainda, meta de 2 uT para a qualidade da ALF a ser recirculada ou remoção mínima de sólidos de $80 \%$ (USEPA, 2002).

No Brasil, não se dispõe de normas técnicas ou legislação específica para o tratamento e recirculação de ALF, mas, por outro lado, é crescente o interesse e a implantação em escala real dessa prática. Torna-se necessária, então, melhor apropriação técnica do problema, incluindo a perspectiva dos riscos potenciais à saúde. A literatura nacional registra vários e importantes trabalhos, realizados na década de 1990 e no início deste século, sobre a caracterização e clarificação de água de lavagem de filtros, reunidos, por exemplo, em Di Bernardo, Scalize e Souza Filho (1999) e Di Bernardo, Di Bernardo e Centurione Filho (2002). Porém, estudos envolvendo a recirculação propriamente dita e a identificação de perigos microbiológicos associados a protozoários são ainda escassos.

O objetivo do presente trabalho é avaliar o potencial de introdução de perigos associados à recirculação de ALF em estações de tratamento de água, utilizando experimentos em escala piloto, variando características como turbidez, razão de recirculação e utilização de tratamento prévio (clarificação com e sem condicionamento químico).

\section{Material e métodos}

Como etapa inicial dos trabalhos, procedeu-se à caracterização, em escala real, da ALF da ETA da Universidade Federal de Viçosa (UFV), Viçosa (MG), e à realização de ensaios de clarificação dessa água em colunas de sedimentação, que serviram à determinação dos parâmetros operacionais para a realização dos ensaios de recirculação de ALF em instalação piloto.

\section{Caracterização da água de lavagem de filtro da ETA-UFV e da ETA piloto}

Para a caracterização da ALF foram realizados dez eventos de amostragem em cada um dos dois filtros da ETA-UFV (ALF1 e ALF2) e do filtro da ETA piloto (EP), com amostras compostas, coletadas a cada 30 segundos durante a operação de lavagem (cerca de 10 minutos) e analisadas para as variáveis físicas, químicas e microbiológicas: turbidez, alcalinidade, alumínio, manganês, demanda química de oxigênio (DQO), sólidos totais em suspensão (SST), sólidos sedimentáveis, cistos de Giardia spp. e oocistos de Cryptosporidium spp.

\section{Ensaios de clarificação da água de lavagem de filtros da ETA-UFV em colunas de sedimentação}

As amostras de ALF da ETA-UFV foram colocadas em colunas de sedimentação (construídas em PVC, com capacidade de 21 L, diâmetro de $15 \mathrm{~cm}$ e altura de $120 \mathrm{~cm}$ ), mantidas sob agitação correspondente a gradiente de velocidade de $100 \mathrm{~s}^{-1}$; a seguir, o agitador era desligado e o clarificado era coletado a cada quatro minutos em um ponto localizado a $7 \mathrm{~cm}$ do fundo para a determinação da turbidez. Nesses ensaios, foram testados três tipos de polímeros: não-iônico (N 3100L), catiônico (K 122L) e aniônico (A 3015L). Inicialmente, foram fixados o tempo de mistura (5 minutos) e a concentração do polímero ( 3 g. $\left.\mathrm{L}^{-1}\right)$, variando-se as doses em 2, 5, 7 e $10 \mathrm{mg} . \mathrm{L}^{-1}$. De posse da melhor dose para os três polímeros testados, passou-se, então, a variar a concentração dos polímeros em 1,0; 3,0 e 6,0 g. $\mathrm{L}^{-1}$. Fixada a melhor concentração, as doses foram novamente variadas em torno dos melhores resultados encontrados nos primeiros ensaios. Esses ensaios foram realizados com valores de turbidez da ALF em torno de $70 \mathrm{uT}$ sendo o tempo de mistura mantido em 5 min. Encontrado o melhor par de valores dose/concentração, o tempo de mistura foi variado entre em 3, 5, 7, e $10 \mathrm{~min}$. Selecionadas as melhores doses, 
concentrações de polímeros e tempos de mistura, foram realizados novos ensaios, um para cada polímero, com turbidez da ALF em torno de 35 uT. Nesses ensaios, o sobrenadante foi coletado e caracterizado pelas variáveis físicas, químicas e microbiológicas, citadas no item anterior, além de $\mathrm{pH}$, ferro, cor aparente, coliformes totais e Escherichia coli.

\section{Ensaios de recirculação da água de lavagem do filtro da ETA piloto}

Para realização dos ensaios, foi instalada uma unidade de tratamento piloto em ciclo completo, construída em chapas de aço, buscando-se reproduzir a configuração e os parâmetros de operação da ETA-UFV.

A ETA-UFV trata cerca de 50 L.s ${ }^{-1}$, sendo empregado o tratamento convencional (ciclo completo): coagulação com sulfato de alumínio granulado, mistura rápida hidráulica em calha Parshall, floculação hidráulica (floculação com seis câmaras e orifícios retangulares de passagem, dispostos alternadamente nos cantos inferiores esquerdos e superiores direitos), decantador circular com alimentação central e fluxo radial (taxa de aplicação superficial de $20 \mathrm{~m}^{3} \cdot \mathrm{m}^{2}$ . $\left.\mathrm{d}^{-1}\right)$ e dois filtros rápidos (taxa de filtração de $220 \mathrm{~m}^{3} \cdot \mathrm{m}^{-2} \cdot \mathrm{d}^{-1}$ ).

A EP, alimentada com a mesma $\mathrm{AB}$ da ETA-UFV, era composta por misturador rápido (diafragma instalado na tubulação de entrada da EP), floculador hidráulico (seis câmaras com a mesma configuração descrita para a ETA-UFV), decantador circular de fluxo ascendente, filtro rápido descendente com camada simples de areia e clarificador para ALF. A EP foi dimensionada para vazão de 0,36 $\mathrm{m}^{3} \cdot \mathrm{h}^{-1}\left(0,1 \mathrm{~L} \cdot \mathrm{s}^{-1}\right)$. Nos experimentos de recirculação de ALF, foram aplicadas vazões totais de $0,378 \mathrm{~m}^{3} \cdot \mathrm{h}^{-1} ; 0,396 \mathrm{~m}^{3} \cdot \mathrm{h}^{-1} ; 0,414 \mathrm{~m}^{3} \cdot \mathrm{h}^{-1}$ e $0,432 \mathrm{~m}^{3} \cdot \mathrm{h}^{-1}$, correspondentes às razões de recirculação de ALF de 5\%, 10\%, 15\% e 20\%. Na Tabela 1, apresentam-se informações sobre a configuração da EP e dos parâmetros de operação para a vazão de projeto.

A retrolavagem do filtro da EP era realizada com água tratada (clorada), proveniente do reservatório elevado da ETA-UFV. O tempo de lavagem foi o mesmo da ETA-UFV, 10 minutos, o que proporcionava um volume de ALF de 260 L. A ALF era encaminhada para o clarificador, de onde era bombeada para a entrada da EP. O clarificador apresentava altura útil de 1,2 $\mathrm{m}$, área superficial de 0,3 $\mathrm{m}^{2} \mathrm{e}$ possuía uma hélice acoplada a um motor, proporcionando gradiente de velocidade de $300 \mathrm{~s}^{-1}$.

Para avaliar os efeitos da recirculação da ALF, foi realizado um ensaio para cada condição experimental e testadas as situações:

(i) recirculação sem promover a clarificação da ALF: nessa situação, a ALF permanecia em agitação enquanto era recirculada;

(ii) recirculação com clarificação e adição de polímero: o melhor resultado obtido nos ensaios de sedimentação em colunas (tipo de polímero, concentração, dose e tempo de mistura) foi adotado nos testes na EP. A ALF era introduzida no clarificador com agitação correspondente a gradiente de velocidade de $300 \mathrm{~s}^{-1} \mathrm{e}$ mantida por 10 minutos após a aplicação do polímero; depois de desligado o agitador, a ALF permanecia em repouso por 40 minutos e, decorrido esse tempo, foi dado início ao ensaio de recirculação

(iii) recirculação com clarificação sem adição de polímero: nesses ensaios, o agitador era ligado com agitação correspondente ao gradiente de velocidade de $300 \mathrm{~s}^{-1}$ por 5 minutos; após isso era desligado e a ALF, mantida em repouso por 2 horas, sendo, então, iniciado o ensaio.

Previamente a todos os ensaios na EP, foram realizados testes de jarros (Jar test) para a definição das condições ótimas de coagulação (pH/dose de coagulante). Além disso, com o objetivo de verificar eventuais impactos da recirculação da ALF no processo de tratamento da água, foram executados ensaios controle sem recirculação da ALF, um para cada vazão testada.

Os parâmetros de controle para todos os ensaios, em amostras de $A B$, sobrenadante da ALF clarificada, mistura entre AB e ALF, água decantada e água filtrada foram: turbidez, cistos de Giardia spp. e oocistos de Cryptosporidium spp. Em todos os ensaios, as amostras eram coletadas de hora em hora, durante as carreiras de filtração (aproximadamente sete horas), a partir da terceira hora de cada carreira. Isso porque a ETA-UFV opera por, aproximadamente, sete horas e o tempo de detenção da EP era de, aproximadamente, três horas.

\section{Análises laboratoriais}

As variáveis físicas, químicas e bacteriológicas foram determinadas de acordo com os seguintes métodos, especificados no Standard

Tabela 1 - Dimensões e parâmetros operacionais da ETA piloto

\begin{tabular}{|c|c|c|c|c|c|c|}
\hline Unidades e dimensões & \multicolumn{6}{|c|}{ Parâmetros e valores } \\
\hline Mistura rápida & \multicolumn{6}{|c|}{ Gradiente de velocidade: $1.000 \mathrm{~s}^{-1}$} \\
\hline Floculador & \multicolumn{6}{|c|}{ Gradientes de velocidade $\left(\mathrm{s}^{-1}\right)$ nas câmaras } \\
\hline$C=1,10 \mathrm{~m}$ & 1 & 2 & 3 & 4 & 5 & 6 \\
\hline $\mathrm{L}=0,21 \mathrm{~m}$ & 62 & 48 & 34 & 27 & 22 & 16 \\
\hline $\mathrm{h}=0,70 \mathrm{~m}$ & \multicolumn{6}{|c|}{ Tempo de detenção hidráulica: 20 minutos } \\
\hline \multicolumn{7}{|l|}{ Decantador } \\
\hline$A=0,44 m^{2}$ & \multicolumn{6}{|c|}{ Taxa de aplicação superficial: $20 \mathrm{~m}^{3} \cdot \mathrm{m}^{-2} \cdot \mathrm{d}$} \\
\hline \multicolumn{7}{|l|}{$\mathrm{h}=3,3 \mathrm{~m}$} \\
\hline Filtro & \multicolumn{6}{|c|}{ Taxa de filtração: $220 \mathrm{~m}^{3} \cdot \mathrm{m}-{ }^{2} \cdot d$} \\
\hline$A=0,04 m^{2}$ & \multicolumn{6}{|c|}{ Granulometria areia: def $=0,41 \mathrm{~mm} ; \mathrm{CU} \leq 1,3$} \\
\hline $\mathrm{ha}=0,25 \mathrm{~m}$ & \multicolumn{6}{|c|}{$\begin{array}{l}\text { Granulometria seixo rolado: } d \min =1 \mathrm{~mm} \\
\qquad d \max =19 \mathrm{~mm}\end{array}$} \\
\hline \multicolumn{7}{|l|}{$\mathrm{hsr}=0,28 \mathrm{~m}$} \\
\hline
\end{tabular}


methods for the examination of water and wastewater (APHA, AWWA, WEF, 2005): turbidez (método 2130-B), cor (2120 B), pH (4500 B), alcalinidade (2320-B), alumínio (3500-Al B), manganês (3500-Mn), ferro (3500-Fe B), DQO (5220 D), sólidos totais em suspensão (2540-B), sólidos sedimentáveis (2540 F) e coliformes (9223 B). A pesquisa de cistos de Giardia spp. e oocistos de Cryptosporidium spp. foi realizada com o emprego da técnica de floculação com carbonato de cálcio para a etapa de concentração (Vesey et al, 1993), seguida da identificação e enumeração por imunofluorescência direta utilizando kit Merifluor ${ }^{\circledR}$.

\section{Sistematização e análise dos dados}

Nos ensaios de recirculação da ALF da EP, os resultados das determinações de turbidez foram apresentados em termos de médias dos valores das coletas horárias ao longo da carreira de filtração. Os resultados da pesquisa de protozoários expressam os valores encontrados em amostras compostas das coletas horárias.

Foram aplicados os testes estatísticos não-paramétricos:

(i) teste de Kruskal-Wallis, para a determinação de diferenças entre médias das variáveis de caracterização da ALF da EP e da ETA-UFV;

(ii) coeficiente de correlação de Spearman para determinar o grau de associação entre duas variáveis mensuradas e dispostas em postos ordenados - concentrações de cistos de Giardia spp. e oocistos de Cryptosporidium spp. e valores de turbidez da AB;

(iii) coeficiente Phi para verificar a associação de variáveis mensuradas a nível nominal e que se apresentam de modo dicotômico - ocorrência de cistos de Giardia spp. e de oocistos de Cryptosporidium spp. (presença / ausência) em faixas de turbidez da AB e da ALF superiores ou inferiores a determinado valor. Os valores de turbidez para esse teste (5,8 uT e 11,3 uT) foram selecionados no banco de dados de monitoramento da ALF, procurando-se valores próximos de $5 \mathrm{uT}$, presente em recomendações para recirculação

Tabela 2 - Caracterização da água de lavagem de filtro, ETA piloto e ETAUFV, valores médios (1) (2)

\begin{tabular}{|c|c|c|c|}
\hline \multirow{2}{*}{ Parâmetro } & \multicolumn{2}{|c|}{ ETA-UFV } & \multirow{2}{*}{ ALF piloto ${ }^{(3)}$} \\
\hline & ALF $1^{(3)}$ & ALF $2^{(3)}$ & \\
\hline DQO (mg L-1) & $49,1 \mathrm{a}$ & $46,8 a$ & $30,7 a$ \\
\hline Alumínio (mg L-1) & $1,6 \mathrm{a}$ & $1,5 a$ & $0,1 b$ \\
\hline Manganês (mg L-1) & $3,0 a$ & $2,7 a$ & $0,2 b$ \\
\hline Alcalinidade (mg CaCO $\mathrm{L}^{-1}$ ) & 17,9 a & $19,5 a b$ & $22,1 b$ \\
\hline Turbidez (uT) & $52,4 \mathrm{a}$ & $49,6 a$ & $58,4 \mathrm{a}$ \\
\hline Sólidos Totais em Suspensão (mg L ${ }^{-1}$ ) & $62,3 \mathrm{a}$ & $46,9 a b$ & $52,7 b$ \\
\hline Sólidos sedimentáveis (mL. $\left.\mathrm{L}^{-1}\right)$ & $3,3 a$ & $3,3 a$ & $1,1 b$ \\
\hline Giardia spp. ${ }^{(4)(5)}$ & 9,27 & 4,57 & 0,9 \\
\hline Cryptosporidium spp. (5) (6) & 10,09 & 1,79 & 3,57 \\
\hline
\end{tabular}

Notas: (1) amostras compostas ao longo do período de lavagem dos filtros; (2) letras iguais nas mesmas linhas indicam a não existência de diferenças significativas entre médias (teste de Kruskal-Wallis; $p>0,05$ ); (3) $n=10$; médias aritméticas, à exceção de cistos de Giardia spp. e oocistos de Cryptosporidium spp., calculados por média geométrica; (4) cistos. L $^{-1}$ (5) teste estatístico não realizado por insuficiência de dados $(n=5)$; (6) oocistos. $L^{-1}$. de ALF no Reino Unido (UKWIR, 1998) e de 10 uT (o dobro da referida recomendação). Todos os testes estatísticos foram realizados com a utilização do programa Biostat 2.0, assumindo nível de significância de 5\%.

\section{Resultados e discussão}

\section{Caracterização da água de lavagem de filtro da ETA-UFV e da ETA piloto}

Em geral, a ALF da ETA-UFV (ALF1 e ALF2) e da EP apresentaram valores de DQO, turbidez e sólidos relativamente próximos entre si, embora tenham por vezes diferido estatisticamente (Tabela 2). Os valores de DQO encontrados no presente estudo (30-50 mg.L-1) encontram respaldo na literatura nacional (DI BERNARDO, DI BERNARDO e CENTURIONE FILHO, 2002). Os valores de turbidez e sólidos em suspensão revelam-se baixos quando comparados com os registrados por Souza Filho e Di Bernardo (1999) (130-240 uT e 210-395 mg..-1) e Medeiros, Sanches e Junk (2003) (130 mg SST.L-1), porém mais próximos aos encontrados por Scalize e Di Bernardo (2000) (60 uT e 58 mg. $\left.\mathrm{L}^{-1}\right)$. De fato, a literatura registra amplas variações de turbidez e SST em ALF; por exemplo, Di Bernardo, Di Bernardo e Centurione Filho (2002) citam faixas de 50-170 uT e 90-370 mg SST.L ${ }^{-1}$. Tobiason et al (2003) observaram valores de turbidez média de amostras compostas de 150 a 400 uT em três ETAs nos Estados Unidos. Também devem ser consideradas variações ao longo do período de lavagem dos filtros. Souza Filho e Di Bernardo (1999) encontraram picos de turbidez e de SST de até 700 uT e 1.200 mg.L-1, 90 segundos após o início da lavagem do filtro. No presente estudo, os picos de turbidez na ETA-UFV e na EP foram de, respectivamente 100-200 uT e $400 \mathrm{uT}, 1^{\circ}$ e $2^{\circ}$ minutos após o início da lavagem dos filtros.

De forma similar, os teores de sólidos sedimentáveis (1,1-3,3 mL. $\mathrm{L}^{-1}$ ) podem ser considerados baixos quando comparados, por exemplo, com os encontrados por Souza Filho e Di Bernardo (1999) (15-90 mL.L-1), mas encontram registros similares na literatura nacional (DI BERNARDO, DI BERNARDO e CENTURIONE FILHO, 2002). Por fim, as concentrações de cistos de Giardia spp. e oocistos Cryptosporidium spp., detectadas na ALF da ETA-UFV e da EP, encontram correspondência com relatos na literatura internacional, por exemplo, em USEPA (2001) (médias de 2,03 cistos de Giardia spp. e 1,75 oocistos de Cryptosporidium spp. por litro) e em Arota, Giovanni e LeChevalier (2001) (médias de 4,5 cistos de Giardia spp. e oocistos de Cryptosporidium spp. por litro).

\section{Ensaios de clarificação da ALF da ETA-UFV em colunas de sedimentação}

$\mathrm{Na}$ primeira etapa dos ensaios em coluna de sedimentação (determinação do melhor par de valores dose/concentração dos 
polímeros), independentemente do produto, a utilização de menores doses ( 1 mg. $\mathrm{L}^{-1}$ ) em concentrações de 1,0 e 3,0 g.L.-1 proporcionou os melhores resultados, caracterizados pela combinação de velocidade de sedimentação elevada e turbidez remanescente mais baixa. Com base nesses resultados, optou-se por continuar os ensaios com a concentração de 1,0 g.L $\mathrm{L}^{-1}$ para os três tipos de polímeros. Na etapa seguinte (avaliação dos tempos de mistura), para o polímero catiônico, os maiores tempos de mistura proporcionaram claro aumento na velocidade de sedimentação e menores valores de turbidez remanescente, sendo o melhor resultado obtido com o tempo de 10 minutos. Para o polímero não-iônico, a partir de 5 minutos de agitação, essa relação não se mostrou tão clara e, assim, a escolha recaiu no tempo de mistura de 5 minutos. Em relação ao polímero aniônico, os tempos de mistura de sete e dez minutos foram os que resultaram em menores valores de turbidez remanescente (4,8 e 3,8 uT, respectivamente) com valores de velocidade de sedimentação semelhantes; porém, como o tempo de mistura de sete minutos já atendia à recomendação de recirculação, citada anteriormente, com turbidez menor que 5 uT (UKWIR, 1998), este foi o tempo adotado. Na Tabela 3, encontram-se os melhores resultados obtidos para cada polímero, apresentados de forma resumida, de acordo com a série de ensaios descritos no item Ensaios de clarificação da ALF da ETA-UFV em colunas de sedimentação. Nota-se que o polímero catiônico foi o que proporcionou o melhor resultado, com velocidade de sedimentação de $21 \mathrm{~cm} \mathrm{~min}^{-1}$ e turbidez final de 3,8 uT, comparativamente a 9,5 $\mathrm{cm} \mathrm{min}^{-1}$ e 4,8 uT com o polímero aniônico e $8,1 \mathrm{~cm} \mathrm{~min}^{-1}$ e 5,5 uT com o polímero não-iônico.

Na Figura 1, encontra-se a curva de variação da turbidez residual em função do tempo de sedimentação para os quatro ensaios de clarificação da ALF, realizados de acordo com os parâmetros descritos na Tabela 3. A curva de sedimentação e a eficiência de remoção de turbidez foram bastante semelhantes às dos ensaios anteriores, resultando em valores de turbidez, ao final do ensaio, de 1,6 e 2,1 uT, para os polímeros catiônico e aniônico, respectivamente. Em relação ao ensaio sem aplicação de polímeros, a turbidez, após 44 minutos, foi de 12,8 uT e a velocidade de sedimentação, de 2,2 $\mathrm{cm} \mathrm{min}^{-1}$.

Os resultados dos quatro ensaios de caracterização do sobrenadante clarificado da ALF estão apresentados na Tabela 4.

A aplicação de polímeros proporcionou remoção considerável de todas as variáveis físicas e químicas, exceto DQO (41,2\% de remoção); a remoção de alumínio e manganês resultou em níveis não detectáveis desses elementos. Nas condições desses ensaios, a utilização do polímero catiônico proporcionou as menores concentrações dos diversos parâmetros e os piores resultados referem-se ao ensaio sem aplicação de polímeros. Em ensaios em colunas de sedimentação, Souza Filho e Di Bernardo (1999) também concluíram que a sedimentabilidade dos sólidos de ALF foi superior, quando condicionadas com polímeros (catiônico, aniônico e nãoiônico); os melhores resultados foram obtidos com polímero aniônico ( $\left.1 \mathrm{mg} . \mathrm{L}^{-1}\right)$, sendo registradas as seguintes reduções entre a ALF bruta e clarificada: turbidez (de 130 para 0,87 uT), cor aparente (de 2.000 para $5 \mathrm{uC}$ ), DQO (de 40,9 para 19,6 mg..-1), SST (de 250 para $\left.1 \mathrm{mg} . \mathrm{L}^{-1}\right)$. Scalize e Di Bernardo (2000) também reportaram resultados superiores com polímero aniônico (1,4-6,0 mg. $\left.\mathrm{L}^{-1}\right)$ - comparativamente à sedimentação em colunas sem a aplicação de polímero - na clarificação de ALF com 60-232 uT e 58-248

Tabela 3 - Velocidades de sedimentação e turbidez remanescente dos ensaios finais realizados com polímeros catiônico, aniônico e não-iônico

\begin{tabular}{|c|c|c|}
\hline $\begin{array}{l}\text { Caracterização dos ensaios } \\
\text { com melhores resultados } \\
\text { para cada polímero }\end{array}$ & $\begin{array}{l}\text { Velocidade de } \\
\text { sedimentação } \\
\left(\mathrm{cm} \cdot \mathrm{min}^{-1}\right)\end{array}$ & $\begin{array}{l}\text { Turbidez } \\
\text { remanescente } \\
\text { (uT) }\end{array}$ \\
\hline $\begin{array}{l}\text { Polímero catiônico - } 1,0 \text { g. } \mathrm{L}^{-1} \text {; } \\
\text { dose de } 1 \mathrm{mg} \cdot \mathrm{L}^{-1} \text {; tempo de } \\
\text { mistura de } 10 \text { minutos }\end{array}$ & 21 & 3,8 \\
\hline $\begin{array}{l}\text { Polímero aniônico - } 1,0 \text { g. } \mathrm{L}^{-1} \text {; } \\
\text { dose de } 1 \mathrm{mg} \cdot \mathrm{L}^{-1} ; \text { tempo de } \\
\text { mistura de } 7 \text { minutos }\end{array}$ & 9,5 & 4,8 \\
\hline $\begin{array}{l}\text { Polímero não-iônico - } 1,0 \mathrm{~g} \cdot \mathrm{L}^{-1} \text {; } \\
\text { dose de } 1 \mathrm{mg} \cdot \mathrm{L}^{-1} \text {; tempo de } \\
\text { mistura de } 5 \text { minutos }\end{array}$ & 8,1 & 5,5 \\
\hline
\end{tabular}

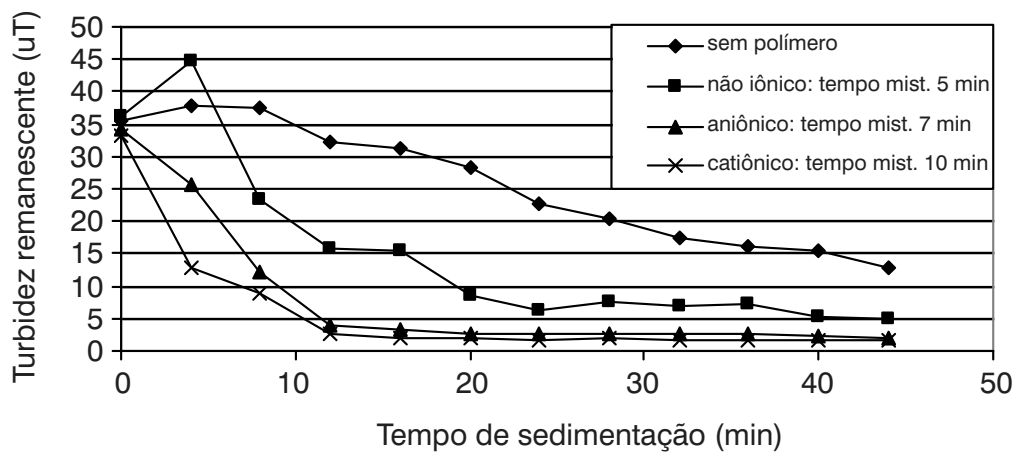

Figura 1 - Ensaio de clarificação da água de lavagem dos filtros , turbidez remanescente em função do tempo de sedimentação, polímero catiônico: dose $=1 \mathrm{mg} \cdot \mathrm{L}^{-1}$, concentração $=1,0 \mathrm{~g} \cdot \mathrm{L}^{-1} \mathrm{e}$ tempo de mistura $=10$ minutos; polímero não-iônico: dose $=1 \mathrm{mg} \cdot \mathrm{L}^{-1}$, concentração $=1,0 \mathrm{~g} \cdot \mathrm{L}^{-1} \mathrm{e}$ tempo de mistura $=5$ minutos; polímero aniônico: dose $=1 \mathrm{mg} \cdot \mathrm{L}^{-1}$, concentração $=1,0 \mathrm{~g} \cdot \mathrm{L}^{-1}$ e tempo de mistura $=7$ minutos 
Tabela 4 - Composição da água de lavagem dos filtros e das amostras clarificadas

\begin{tabular}{|c|c|c|c|c|c|}
\hline Parâmetro & ALF bruta & Sem polímero & Aniônico & Catiônico & Não-iônico \\
\hline $\mathrm{DQO}\left(\mathrm{mg} \mathrm{L}^{-1}\right)$ & 46,6 & 30,8 & 27,4 & 27,4 & 30 \\
\hline Ferro $\left(\mathrm{mg} \mathrm{L}^{-1}\right)$ & 3,5 & 2,1 & 0,2 & 0,1 & 0,3 \\
\hline Alumínio (mg L-1) & 0,6 & 0,01 & $\mathrm{ND}^{*}$ & ND & ND \\
\hline Manganês (mg L-1) & 0,1 & ND & ND & ND & ND \\
\hline Alcalinidade total $\left(\mathrm{mg} \mathrm{CaCO}_{3} \mathrm{~L}^{-1}\right)$ & 17,3 & 17,3 & 17,3 & 17,3 & 17,3 \\
\hline $\mathrm{pH}$ & 7,7 & 7,7 & 7,6 & 7,6 & 7,7 \\
\hline Cor (uH) & 150 & 45 & 10 & 10 & 10 \\
\hline Turbidez (uT) & 33,5 & 12,8 & 2,1 & 1,5 & 4,9 \\
\hline Sólidos em Suspensão Totais (mg L-1) & 75 & 29,5 & 7 & 7 & 10,5 \\
\hline Sólidos Sedimentáveis (mL L-1) & 3 & 0,4 & ND & ND & ND \\
\hline Coliformes totais (NMP por $100 \mathrm{~mL}$ ) & $2,3 \times 10^{1}$ & ND & ND & ND & ND \\
\hline Escherichia coli (NMP por 100mL) & ND & ND & ND & ND & ND \\
\hline Cryptosporidium spp. (oocistos. L-1 $^{-1}$ ) & ND & $3,0 \times 10^{1}$ & 5 & ND & 4 \\
\hline Giardia spp. (cistos. $\mathrm{L}^{-1}$ ) & ND & $1,0 \times 10^{1}$ & ND & ND & ND \\
\hline
\end{tabular}

* ND: não detectado.

mg SST.L ${ }^{-1}$; o sobrenadante clarificado com o polímero apresentou, aproximadamente, 7-9 uT e 16-18 $\mathrm{mg} \mathrm{SST.L}^{-1}$

A não ocorrência de coliformes totais e de Escherichia coli pode ter sido devida à utilização de água tratada (clorada) na lavagem do filtro. Essa hipótese é reforçada em outro trabalho com a ALF da ETA-UFV, no qual bactérias do grupo coliforme foram encontradas na ALF em concentrações inferiores às da AB e a ALF apresentava, durante o período de lavagem dos filtros, concentrações de cloro livre de 0,02 a 1,13 $\mathrm{mg} \mathrm{L}^{-1}$; por outro lado, organismos mais resistentes à ação do cloro, tais como esporos de bactérias aeróbias e anaeróbias, Bacillus subtilis e Clostridium perfringens, foram encontrados em concentrações mais elevadas na ALF do que na AB (Braga et al, 2006). No trabalho de Medeiros, Sanches e Junk (2003), também não foram detectados coliformes totais e coliformes termotolerantes na ALF. A ausência de valores detectáveis de cistos de Giardia spp. e oocistos Cryptosporidium spp. na ALF pode estar relacionada a limitações da técnica de detecção, uma vez que, ao longo do monitoramento da ALF, eles foram identificados (Tabela 2). Dessa forma, embora na amostra utilizada nos ensaios não tenham sido detectados tais protozoários, estes, sem dúvida, podem estar presentes na ALF, já que se observou a presença de cistos de Giardia spp. e oocistos de Cryptosporidium spp. em amostras de água clarificada sem que os mesmos tivessem sido identificados na ALF utilizada nos ensaios (Tabela 4).

\section{Ensaios de recirculação da água de lavagem do filtro da ETA piloto}

O polímero catiônico forneceu os melhores resultados nos ensaios de sedimentação em colunas, sendo, portanto, selecionado para os ensaios na $\mathrm{EP}$ (dose $=1 \mathrm{mg} . \mathrm{L}^{-1}$; concentração $=1,0 \mathrm{~g} . \mathrm{L}^{-1}$ e tempo de mistura $=10$ minutos). Na Tabela 5, encontram-se os resultados dos ensaios na EP de recirculação de água da ALF, clarificada com aplicação de polímero catiônico.

Nesses ensaios, foram detectados cistos de Giardia spp. em todas as amostras de $\mathrm{AB}$, com valores variando entre 25 e 47 cistos $\mathrm{L}^{-1}$. Oocistos de Cryptosporidium spp. foram detectados em duas das quatro amostras analisadas, tendo como valor máximo 60 oocistos $\mathrm{L}^{-1}$. Na ALF clarificada, em dois dos ensaios realizados não foram detectados cistos de Giardia spp. e, em três, não foram detectados oocistos de Cryptosporidium spp. Apesar de terem sido encontrados protozoários tanto na $\mathrm{AB}$ quanto na ALF clarificada, oocistos foram detectados na mistura entre $A B$ e ALF apenas no ensaio em que se testou 0,015 L.s ${ }^{-1}$ de ALF + 0,1 L.s s $^{-1}$ de AB. Ao longo do tratamento na EP, apenas cistos de Giardia spp. foram detectados, em somente uma amostra de água decantada, com razão de recirculação de 15\%.

Na Tabela 6, são apresentados os resultados dos ensaios em que a ALF foi clarificada por duas horas, sem utilização de polímero. Esses ensaios foram executados com valores baixos de turbidez da $\mathrm{AB}$, sempre menores que 12,2 uT. Isso provavelmente influenciou a presença, também reduzida, de protozoários tanto na $A B$ quanto na ALF clarificada. A reciclagem da ALF clarificada praticamente não influenciou a turbidez da água afluente à EP, uma vez que a turbidez da mistura entre $\mathrm{AB}$ e ALF foi muito próxima à da $\mathrm{AB}$, independentemente da razão de recirculação. Cistos de Giardia spp. e oocistos de Cryptosporidium spp. não foram detectados nas amostras de água decantada e filtrada.

$\mathrm{Na}$ Tabela 7, são apresentados os resultados dos ensaios na EP em que se reciclou a ALF sem clarificá-la, mantendo-a sob agitação. A não clarificação da ALF provavelmente influenciou a presença de Cryptosporidium spp., já que foram detectados oocistos em três das 
Tabela 5 - Resultados dos ensaios de recirculação de água de lavagem de filtro na ETA piloto, clarificação com polímero catiônico

\begin{tabular}{|c|c|c|c|c|c|c|}
\hline Razão de recirculação & Parâmetro & $A B$ & Água decantada & Água filtrada & ALF & Mistura $A B+A L F$ \\
\hline \multirow[t]{3}{*}{$5 \%(1)$} & Turbidez ${ }^{(5)}$ & 42,7 & 10,8 & 1,1 & 3,9 & 40,6 \\
\hline & Cryptosporidium ${ }^{(6)}$ & ND & ND & ND & 4 & ND \\
\hline & Giardia $^{(7)}$ & 47 & ND & ND & 4 & ND \\
\hline \multirow[t]{3}{*}{$10 \%{ }^{(2)}$} & Turbidez ${ }^{(5)}$ & 19,4 & 8,9 & 2,2 & 4,4 & 17,7 \\
\hline & Cryptosporidium ${ }^{(6)}$ & 10 & ND & ND & ND & ND \\
\hline & Giardia $^{(7)}$ & 40 & ND & ND & ND & ND \\
\hline \multirow[t]{3}{*}{$15 \%{ }^{(3)}$} & Turbidez ${ }^{(5)}$ & 174 & 30 & 1,4 & 5,5 & 150,5 \\
\hline & Cryptosporidium (6) & ND & ND & ND & ND & 20 \\
\hline & Giardia $^{(7)}$ & 25 & 10 & ND & 25 & 20 \\
\hline \multirow[t]{3}{*}{$20 \%{ }^{(4)}$} & Turbidez ${ }^{(5)}$ & 179 & 25 & 2,1 & 5,8 & 165 \\
\hline & Cryptosporidium (6) & 60 & ND & ND & ND & ND \\
\hline & Giardia $^{(7)}$ & 30 & ND & ND & ND & ND \\
\hline
\end{tabular}

NOTAS: (1) 0,005 L.s ${ }^{-1} \mathrm{ALF}+0,1 \mathrm{~L} . \mathrm{s}^{-1} \mathrm{AB}$; (2) 0,01 L.s ${ }^{-1} \mathrm{ALF}+0,1 \mathrm{~L} . \mathrm{s}^{-1} \mathrm{AB}$; (3) 0,015 L.s. $\mathrm{s}^{-1} \mathrm{ALF}+0,1 \mathrm{~L}$. $\mathrm{s}^{-1} \mathrm{AB}$; (4) 0,020 L.s ${ }^{-1} \mathrm{ALF}+0,1 \mathrm{~L} . \mathrm{s}^{-1} \mathrm{AB}$; (5) uT, valores médios ao longo da carreira de filtração; (6) oocistos. $L^{-1}$, valores de amostras compostas ao longo da carreira de filtração; (7) cistos. $L^{-1}$, valores de amostras compostas ao longo da carreira de filtração; $A B$ : água bruta; ALF: água de lavagem do filtro pós-clarificação; ND: não detectado.

Tabela 6 - Resultados dos ensaios de recirculação de água de lavagem de filtro na ETA piloto, clarificação sem utilização de polímero

\begin{tabular}{|c|c|c|c|c|c|c|}
\hline Razão de recirculação & Parâmetro & $A B$ & Água decantada & Água filtrada & ALF & Mistura $\mathrm{AB}+\mathrm{ALF}$ \\
\hline \multirow[t]{3}{*}{$5 \%(1)$} & Turbidez ${ }^{(5)}$ & 8,4 & 7,8 & 1,9 & 16,5 & 8,4 \\
\hline & Cryptosporidium ${ }^{(6)}$ & ND & ND & ND & ND & ND \\
\hline & Giardia $^{(7)}$ & ND & ND & ND & 10 & ND \\
\hline \multirow[t]{3}{*}{$10 \%^{(2)}$} & Turbidez ${ }^{(5)}$ & 12,2 & 7,4 & 0,4 & 16,4 & 13 \\
\hline & Cryptosporidium ${ }^{(6)}$ & ND & ND & ND & ND & ND \\
\hline & Giardia $^{(7)}$ & ND & ND & ND & ND & ND \\
\hline \multirow[t]{3}{*}{$15 \%{ }^{(3)}$} & Turbidez ${ }^{(5)}$ & 9 & 5,2 & 0,5 & 12,2 & 9,5 \\
\hline & Cryptosporidium (6) & 5 & ND & ND & 8 & ND \\
\hline & Giardia $^{(7)}$ & 5 & ND & ND & ND & ND \\
\hline \multirow[t]{3}{*}{$20 \%{ }^{(4)}$} & Turbidez ${ }^{(5)}$ & 9,8 & 5,7 & 1 & 11,3 & 9,9 \\
\hline & Cryptosporidium ${ }^{(6)}$ & ND & ND & ND & ND & ND \\
\hline & Giardia (7) & 9 & ND & ND & ND & ND \\
\hline
\end{tabular}

NOTAS: (1) 0,005 L.s ${ }^{-1} \mathrm{ALF}+0,1 \mathrm{~L} . \mathrm{s}^{-1} \mathrm{AB}$; (2) 0,01 L.s. ALF + 0,1 L.s ${ }^{-1} \mathrm{AB}$; (3) 0,015 L.s $\mathrm{s}^{-1} \mathrm{ALF}+0,1 \mathrm{~L} . \mathrm{s}^{-1} \mathrm{AB}$; (4) 0,020 L.s ${ }^{-1} \mathrm{ALF}+0,1 \mathrm{~L} . \mathrm{s}^{-1} \mathrm{AB}$; (5) uT, valores médios ao longo da carreira de filtração; (6) oocistos. $L^{-1}$, valores de amostras compostas ao longo da carreira de filtração; (7) cistos. $L^{-1}$, valores de amostras compostas ao longo da carreira de filtração; $A B$ : água bruta; $A L F$ : água de lavagem do filtro pós-clarificação; ND: não detectado.

quatro amostras analisadas, com concentrações variando entre $8 \mathrm{e}$ 16,6 oocistos L $\mathrm{L}^{-1}$. A recirculação da ALF não clarificada provocou aumento da turbidez na mistura entre AB e ALF em comparação à da $\mathrm{AB}$, chegando à elevação de 18,3 uT (AB) para 37,2 uT (mistura), com razão de recirculação de $20 \%$. Caso não haja um controle operacional rígido da ETA, uma alteração dessa magnitude poderá interferir no processo de tratamento. Quanto à presença de protozoários na mistura entre $\mathrm{AB}$ e ALF, merece destaque o fato de que foram detectados oocistos de Cryptosporidium spp. em duas das quatro amostras analisadas, ainda que não tenham sido detectados na $\mathrm{AB}$. No ensaio em que foram recirculados $20 \%$ da ALF, a turbidez média da água filtrada foi de 1,27 uT e se detectou a presença de 2,5 oocistos de Cryptosporidium spp. por litro. Esse resultado merece destaque ainda maior, por representar o único evento em que foram detectados protozoários na água filtrada.

Nos testes controle na EP, simulando-se o tratamento sem recirculação da ALF, foram detectados cistos de Giardia spp. em apenas uma amostra de água decantada e não foram detectados oocistos de Cryptosporidium spp. em nenhuma amostra de água decantada e filtrada (Tabela 8). 
Tabela 7 - Resultados dos ensaios de recirculação de água de lavagem de filtro na ETA piloto, sem clarificação

\begin{tabular}{|c|c|c|c|c|c|c|}
\hline Razão de recirculação & Parâmetro & $A B$ & Água decantada & Água filtrada & ALF & Mistura $A B+A L F$ \\
\hline \multirow[t]{3}{*}{$5 \%{ }^{(1)}$} & Turbidez ${ }^{(5)}$ & 6,6 & 4 & 0,4 & 68,4 & 11,5 \\
\hline & Cryptosporidium ${ }^{(6)}$ & 5 & 1 & ND & 15 & ND \\
\hline & Giardia $^{(7)}$ & ND & ND & ND & ND & ND \\
\hline \multirow[t]{3}{*}{$10 \%{ }^{(2)}$} & Turbidez ${ }^{(5)}$ & 8,5 & 4,6 & 0,9 & 79,7 & 20,1 \\
\hline & Cryptosporidium ${ }^{(6)}$ & ND & ND & ND & ND & 10 \\
\hline & Giardia $^{(7)}$ & ND & ND & ND & ND & ND \\
\hline \multirow[t]{3}{*}{$15 \%{ }^{(3)}$} & Turbidez ${ }^{(5)}$ & 11,2 & 6,4 & 0,7 & 40,1 & 15,4 \\
\hline & Cryptosporidium (6) & ND & ND & ND & 16,6 & ND \\
\hline & Giardia $^{(7)}$ & 10 & ND & ND & 24,9 & ND \\
\hline \multirow[t]{3}{*}{$20 \%(4)$} & Turbidez ${ }^{(5)}$ & 18,3 & 7,5 & 1,3 & 139,7 & 37,3 \\
\hline & Cryptosporidium (6) & ND & ND & 2.5 & 8 & 11 \\
\hline & Giardia $^{(7)}$ & ND & ND & ND & ND & ND \\
\hline
\end{tabular}

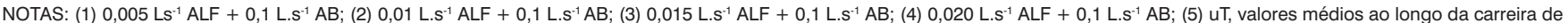
filtração; (6) oocistos. $L^{-1}$, valores de amostras compostas ao longo da carreira de filtração; (7) cistos. $L^{-1}$, valores de amostras compostas ao longo da carreira de filtração; $A B$ : água bruta; $A L F$ : água de lavagem do filtro sem clarificação; ND: não detectado.

Tabela 8 - Resultados dos ensaios sem recirculação da água de lavagem do filtro na ETA piloto

\begin{tabular}{|c|c|c|c|c|}
\hline Vazão (L.s'-1) & Parâmetro & $A B$ & Água decantada & Água filtrada \\
\hline \multirow[t]{3}{*}{0,1} & Turbidez ${ }^{(1)}$ & 35,8 & 12,8 & 1,1 \\
\hline & Cryptosporidium (2) & 52 & ND & ND \\
\hline & Giardia $^{(3)}$ & ND & 10 & ND \\
\hline \multirow[t]{3}{*}{0,105} & Turbidez ${ }^{(1)}$ & 12,2 & 8,7 & 1,1 \\
\hline & Cryptosporidium ${ }^{(2)}$ & ND & ND & ND \\
\hline & Giardia $^{(3)}$ & ND & ND & ND \\
\hline \multirow[t]{3}{*}{0,11} & Turbidez ${ }^{(1)}$ & 12,1 & 9,7 & 1,9 \\
\hline & Cryptosporidium (2) & ND & ND & ND \\
\hline & Giardia $^{(3)}$ & ND & ND & ND \\
\hline \multirow[t]{3}{*}{0,115} & Turbidez ${ }^{(1)}$ & 40,5 & 14,1 & 0,9 \\
\hline & Cryptosporidium (2) & ND & ND & ND \\
\hline & Giardia (3) & 17 & ND & ND \\
\hline \multirow[t]{3}{*}{0,12} & Turbidez ${ }^{(1)}$ & 257,3 & 32,4 & 1,8 \\
\hline & Cryptosporidium (2) & ND & ND & ND \\
\hline & Giardia $^{(3)}$ & ND & ND & ND \\
\hline
\end{tabular}

NOTAS: (1) UT, valores médios ao longo da carreira de filtração; (2) oocistos. $\mathrm{L}^{-1}$, valores de amostras compostas ao longo da carreira de filtração; (3) cistos. $\mathrm{L}^{-1}$, valores de amostras compostas ao longo da carreira de filtração; AB: água bruta; ND: não detectado.

Aparentemente, a julgar pelos valores de turbidez, a recirculação da ALF com incrementos de vazão até 20\% não interferiu no desempenho da EP. Ainda que essa observação mereça cautela em função da limitação do banco de dados, resultados semelhantes foram registrados por Yang et al (2006): em estudo em escala piloto, esses autores não detectaram impactos no tratamento de água com razões de recirculação de ALF de 4,6 e 8\% da vazão da $A B$, sem clarificação da ALF ou com clarificação por 3 minutos, com adição de polímeros.
Em síntese, cistos de Giardia spp. e/ou oocistos de Cryptosporidium spp. foram detectados no efluente do decantador da EP nas seguintes situações:

(i) ensaio sem recirculação da ALF para a vazão de projeto da ETA piloto;

(ii) ensaio de recirculação da ALF com clarificação com polímero catiônico e $15 \%$ de incremento sobre a vazão de projeto; nesse ensaio, a turbidez da $\mathrm{AB}$ e da água decantada era elevada (respectivamente, 174 e $30 \mathrm{uT}$ ) e a turbidez da ALF clarificada era baixa 
( $<5 \mathrm{uT}$ ), tendo sido detectados cistos de Giardia spp. na AB e na ALF clarificada;

(iii) recirculação da ALF sem clarificação e incremento de 5\% sobre a vazão de projeto; nesse caso, foram detectados oocistos de Cryptosporidium spp. na AB e na ALF (turbidez elevada > 60 uT). Na água filtrada da EP, foram detectados oocistos de Cryptosporidium spp. apenas uma vez, quando da recirculação da ALF sem clarificação, com incremento de 20\% sobre a vazão de projeto; nesse ensaio, a elevada turbidez da ALF $(\approx 60 \mathrm{uT}$ ) provocou incremento de cerca de 100\% na turbidez afluente à ETA piloto; oocistos estiveram presentes também na ALF, mas ausentes na AB.

Considerando-se todas as análises realizadas nas amostras de $A B(n=25)$, a presença de cistos de Giardia spp. $\left(r_{s}=0,2121\right.$; $\mathrm{p}=0,3086)$ e oocistos de Cryptosporidium spp. $\left(\mathrm{r}_{\mathrm{s}}=0,2092 ; \mathrm{p}\right.$ $=0,3155)$ não mostrou associação estatisticamente significativa com a turbidez (teste correlação de Spearman). Nas amostras de ALF, a presença ou ausência de cistos de Giardia e oocistos de Cryptosporidium também não revelou associação estatisticamente significativa com valores de turbidez da ALF: > 5,8 uT e $\leq 5,8$ uT $\left(\mathrm{r}_{\Phi}=0,1195 ; \mathrm{p}=0,6547\right),>11,3 \mathrm{uT} \mathrm{e} \leq 11,3 \mathrm{uT}\left(\mathrm{r}_{\Phi}=0,3055\right.$; $\mathrm{p}=0,2850$ ) (teste do coeficiente Phi).

\section{Conclusões}

A caracterização da água ALF da ETA-UFV e da EP confirma que esse efluente apresenta potencial poluidor e de contaminação microbiológica e deve ser tratado antes de seu lançamento em corpos receptores ou de sua recirculação ao processo de tratamento.

Os resultados não permitiram inferências conclusivas sobre a qualidade recomendável da ALF (limites de turbidez) e de limites de vazão de recirculação. Contudo, os resultados obtidos nos ensaios em colunas de sedimentação e na EP demonstraram que a clarificação por sedimentação com o uso de polímeros minimiza os perigos associados à recirculação da ALF.

Recomenda-se a continuidade dos estudos, no sentido de se verificarem os impactos do aumento da carga de cistos de Giardia spp. e oocistos de Cryptosporidium spp. com a recirculação da ALF e a capacidade dos processos unitários de tratamento (decantação e filtração) em absorvê-los. Poder-se-ia, assim, imaginar cenários mais concretos e estimar riscos à saúde, mediante a aplicação da metodologia de avaliação quantitativa de risco microbiológico. Acredita-se que esta é a abordagem mais adequada para subsidiar a formulação de normas a respeito da recirculação da ALF.

\section{Agradecimentos}

À Fundação de Amparo à Pesquisa do Estado de Minas Gerais (FAPEMIG), ao Conselho Nacional de Desenvolvimento Científico e Tecnológico (CNPq), à Financiadora de Estudos e Projetos (FINEP) e à Coordenação de Aperfeiçoamento de Pessoal de Nível Superior (CAPES) pelo aporte de recursos financeiros e/ou de bolsas de mestrado e de iniciação científica.

\section{Referências}

APHA/AWWA/WEF. Standard methods for the examination of water and wastewater. 21. ed. Washington DC: APHA, 2005.

AROTA, H.; GIOVANNI, G.; LECHEVALLIER, M. Spent filter backwash water contaminants and treatment strategies. Journal AWWA, v. 93, n. 5, p. 100-112, 2001.

BRAGA, M. D. etal. Caracterização microbiológica da água de lavagem de filtros e avaliação de diferentes cenários de recirculação. In: CONGRESO INTERAMERICANO DE INGENIERÍA SANITARIA Y AMBIENTAL, 30, Anais..., Punta del Este, Uruguay. Montevideo: AIDIS, 2006. CD-ROM.

DI BERNARDO, L.; DI BERNARDO, A.; CENTURIONE FILHO, P.L. Ensaios de tratabilidade de água e de resíduos gerados em estações de tratamento de água. São Carlos: Rima, 2002.

DI BERNARDO, L.; SCALIZE, P.S.; SOUZA FILHO, A.G. Água de lavagem de filtros rápidos. In: REALI, M.A.P. (Coord.). Noções gerais de tratamento e disposição final de lodos de estações de tratamento de água. Rio de Janeiro: ABES, 1999. p. 143-168 (Projeto Prosab).MEDEIROS, M.A.C.; SANCHES, F.G.; JUNK, M.A.S. Estudo da viabilidade e implantação da recuperação da água de lavagem dos filtros e do lodo dos decantadores da ETA Capim Fino, através da estação de tratamento de lodo - ETL Capim Fino. Limeira: Centro Superior de Educação Tecnológica CESET, 2003.

SCALIZE, P.L.; DI BERNARDO, L. Caracterização da água de lavagem de filtros rápidos de estações de tratamento de água e dos sobrenadantes e sedimentos obtidos após ensaios de clarificação utilizando polímero aniônico. In: CONGRESSO INTERAMERICANO DE INGENIERÍA SANITARIA Y AMBIENTAL, 27, Anais..., Porto Alegre. Rio de Janeiro: Associação Brasileira de Engenharia Sanitária e Ambiental - ABES, 2000. CD ROM

SOUZA FILHO, A.G.; DI BERNARDO, L. Caracterização e clarificação da água de lavagem dos filtros de uma ETA que utiliza cloreto férrico 
como coagulante primário. In: CONGRESSO BRASILEIRO DE ENGENHARIA SANITÁRIA E AMBIENTAL, 20. Anais..., Rio de Janeiro: Associação Brasileira de Engenharia Sanitária e Ambiental - ABES, 1999. CD ROM.

TOBIASON, J.E. et al. Full-scale assessment of waste filter backwash recycle. Journal AWWA, v. 95, n. 7, p. 80-93, 2003.

UNITED KINGDOM WATER INDUSTRY RESEARCH (UKWIR). Guidance manual supporting the water treatment recommendations from the Badenoch group of experts on Cryptosporidium. London: Water Industry Research Limited, 1998.

UNITED STATES ENVIRONMENTAL PROTECTION AGENCY (USEPA). National primary drinking water regulations. Filter backwash recycling rule. Final rule. Washington, DC: EPA (EPA-815-Z-01-001).

Filter backwash recycling rule. Technical guidance manual. Washington, DC: USEPA, Office of Ground Water and Drinking Water. 166p. (EPA 816-R-02-014). Disponível em <http://www.epa.gov/ OGWDW/mdbp/pdf/filterbackwash/fbrr techguidance.pdf $>$. Acesso em 1 jul. 2009.

VESEY, G. et al. A new method for the concentration of Cryptosporidium oocysts from water. Journal of Applied Bacteriology, v. 75, n. 1, p. 82-86, 1993

YANG, C.B. et al. Treatment and reuse of backwash water in Taipei water treatment plant, Taiwan. Water Science and Technology: Water Supply. v.6, n. 6, p. 89-98, 2006. 